\title{
O jovem Boal e a censura ontem e hoje
}

Celso Frederico

Professor titular da Escola de Comunicações e Artes da Universidade de São Paulo. E-mail: celsof@usp.br

Resumo: $\bigcirc$ artigo parte da análise da peça teatral Filha moça, escrita em 1956 pelo dramaturgo Augusto Boal, para ser montada pelo Teatro Experimental do Negro. A peça, que foi totalmente censurada antes mesmo de ser encenada, a exemplo de vários espetáculos da época, dificilmente seria censurada hoje. Embora não se apresenta de forma brutal e direta, como naquela época, a censura da atualidade aparece de outras maneiras mais sutis, mas nem por isso menos eficazes. Os editais, que derivam do poder econômico e do controle público ou privado dos meios de divulgação artística, são, por ironia, uma conquista da classe teatral e também uma forma de censura.

Palavras-chave: Filha moça; Augusto Boal; censura; teatro; editais.
Abstract: The paper analysis the play Filha Moça [Young Daughter], written in 1956 by dramatist Augusto Boal, to be performed by the Teatro Experimental do Negro [The Blackman Experimental Theater]. The play, just like many others at the time, was completely forbidden by the censorship even before it opened, something hard to imagine happening nowadays. Although censorship now may not be as brutal and direct, it still exists and it works through subtler methods as equally effective. Curatorial projects, derivated from the economical power and public or private control of the arts, are, ironically, also a theater class achievement but also a form of censorship.

Keywords: Filha moça; Augusto Boal; censorship; theater; curated projects.

\section{INTRODUÇÃO}

Ao ler o arrazoado dos censores que proibiram a exibição de Filha moça, lembrei-me de uma cena ocorrida em 1968, quando estudava Ciências Sociais na USP. Boal entrou na sala de aula e fez um discurso veemente contra a censura, que, novamente, tentava inviabilizar suas peças. Ele dizia, fazendo gestos com as mãos, que uma obra de arte é um conjunto, uma totalidade. Quando o censor corta um pedaço, o artista não se reconhece mais na obra mutilada. Por isso, concluía: "sou contra toda e qualquer forma de censura".

Naquele momento conturbado, o cerco se fechava contra os artistas. Havia uma deputada, Conceição da Costa Neves, que percorreu o Brasil numa cruzada contra o uso do palavrão no teatro, apontando todos os perigos que isso representava para a família brasileira e para os bons costumes. Lembro ter visto Boal na televisão discutindo com a deputada e defendendo o direito irrestrito à livre manifestação.

Recebido: 08/08/2016 Aprovado: 26/09/2016 
Essas lembranças de Boal retornaram muitos anos depois, quando prestei um concurso na ECA e tive que preparar um ponto sobre a censura. A leitura da bibliografia me fez ver que nunca existiu nenhuma sociedade que não tivesse algum tipo de censura. Portanto, ser contra "toda e qualquer forma de censura”, como dizia Boal, é uma posição irrealista, embora compreensível naquele contexto de mobilização contra a ditadura militar.

Os textos lidos me ensinaram também que existem formas diferentes de censura. Há uma censura direta, brutal: aquela feita pela tesoura do censor. Mas há também outras formas mais sutis, e nem por isso menos eficazes, como as que derivam do poder econômico e do controle público ou privado dos meios de divulgação artística.

Hoje, ninguém proibiria Filha moça. No entanto, as formas sutis de censura continuam operando, como veremos adiante.

$$
* * *
$$

A trajetória artística de Boal foi surpreendente. Por isso, chamou-me a atenção o fato de Filha moça ter sido escrita para o teatro experimental do negro.

Teatro experimental: a expressão define a trajetória de Boal. Ele foi um incansável experimentador, sempre em busca de novas formas: teatro-jornal, teatro-fórum, teatro-imagem e teatro-terapia são manifestações diversas do teatro do oprimido. A cada momento, esse espírito inquieto procurou se reinventar. Não estamos, portanto, diante de um percurso errático. Boal não era um "desbussolado", mas alguém que, a partir de certo momento, comprometeu-se com o projeto de emancipação humana e empenhou-se em entender o papel do teatro como parte integrante desse projeto. Mas, cabe ressaltar, que o jovem engenheiro químico de 25 anos de idade, recém-chegado dos EUA, embora já manifestasse uma sensibilidade social, era alguém distante das questões políticas - um "alienado", como se dizia na época. A politização de Boal se dará posteriormente graças à convivência com artistas politizados ${ }^{1}$. A primeira peça que Boal dirigiu no Arena, como Marido magro, mulher chata, só confirmava a imagem de jovem alienado.

A grande virada de Boal ocorreu a partir de sua participação no Teatro de

1. A atriz Vera Gertel, em suas memórias, fez a seguinte observação a respeito de Boal: "Aí me espantei com seu desconhecimento do passado recente $e$ político do nosso país. Fez até cara de quem não acreditava na existência da repressora ditadura getulista, na prisão e na tortura da oposição". Um gosto amargo de bala. Rio de Janeiro: Civilização Brasileira, 2013, p. 112. Arena e no CPC. Nos tempos de Filha moça, o jovem Boal era um discípulo de Nelson Rodrigues, com quem mantinha diálogo permanente: Boal lhe enviava as primeiras peças ao mestre para ouvir seus conselhos. Há, em Filha moça, a presença de Nelson Rodrigues quem, também, construía personagens que, por razões atávicas, se deixavam levar pelas pulsões inconscientes, pela "tara", pela revelação de uma natureza humana animalesca a qual, como "fatalidade", irrompe misteriosamente e determina o curso de suas vidas.

O engajamento de Boal no início dos anos 1960 não foi um gesto solitário: naquele período, ocorreu uma radicalização política única. Segundo Jacob Gorender, o país viveu "o maior movimento de massas de sua história”. 
O confronto atual entre "coxinhas" e "petralhas" está restrito basicamente às classes médias urbanas, cenário em que o comunismo deixou de ser ameaça.

A intensa mobilização popular no pré-64 contagiou, como era de se esperar, o meio artístico. E aquela movimentação cultural deixou raízes profundas: até hoje é rotineiro nos meios de comunicação entrevistas com artistas de teatro que dizem que tudo, para eles, começou com o CPC. É importante realçar aqui a palavra movimento. Gramsci dizia que "não se pode afirmar que Fulano ou Beltrano se tornarão artistas, mas pode-se afirmar que do movimento nascerão novos artistas"². O CPC não teve relevância estética, não nos deixou obras definitivas. Mas o que importa, aqui, não é o valor estético, mas o valor cultural. A renovação da cultura então proposta deixou uma herança importantíssima no teatro brasileiro.

Boal foi um dos mais ilustres artistas que se revelaram no interior daquele movimento político e artístico.

$$
* * *
$$

Filha moça é um dos momentos iniciais de Boal. Um experimento deixado de lado: o autor nunca se referiu a essa peça juvenil. Recentemente, perguntei ao seu filho, Julián Boal, que disse desconhecer sua existência, desconhecimento compartilhado pela viúva Cecília Boal.

Boal havia chegado dos Estados Unidos. Lá, foi premiado num concurso com a peça Martin pescador. A peça não foi encenada, pois abordava um tema distante para os interesses americanos: os pescadores da Bahia. Boal lembra que seu professor americano, Gassner, fizera também reparos à forma adotada, classificada de "cru naturalismo"3.

A crítica vale também para Filha moça. Boal, assim, começou pelo naturalismo, escolha que terá desdobramentos futuros.

Uma das características básicas do naturalismo é a pretensão de apresentar uma figuração neutra e objetiva da realidade. Entretanto, tal objetivismo está sempre a serviço de uma ideia. Um clássico do naturalismo no Brasil é $O$ cortiço, de Aloísio Azevedo. O próprio título já prefigura o destino dos personagens. Naquele ambiente, não há salvação possível: todos estão entregues à promiscuidade, a incontroláveis impulsos primitivos, são eres animalescos. Trata-se, portanto, de um romance de tese, da explicitação de uma ideia: o homem é fruto do meio ambiente.

O mesmo procedimento encontra-se em Filha moça. Toda a peça é a explicitação de uma tese: onde há miséria não existe amor. Os personagens, portanto, cumprem sua sina, têm o destino selado. A filha age como a mãe, ambas guiadas pelos instintos sexuais. Não há saída, possibilidade de escolher uma nova vida. O eterno retorno do mesmo enquadra os personagens. Sem a dimensão do futuro, da história, a vida social equipara-se à natureza, condenada à repetição.

Para comprovar a tese de fundo, o autor produziu um rebaixamento dos personagens. Todos são indivíduos negativos, entregues à sexualidade mecânica
2. GRAMSCl, Antonio. Cadernos do cárcere. Vol. 6. Rio de Janeiro: Civilização Brasileira, 2002, p. 70.

3. BOAL, Augusto. Hamlet e o filho do padeiro. Memórias imaginadas. São Paulo: Cosac Naify, 2014, p. 149. 
e conformados com o destino. Impossível sentir simpatia por qualquer um: uma filha "galinha", reproduzindo os passos da mãe; o pai, um corno manso conformado; a vizinha, uma alcoviteira.

Para a censura, a representação da família brasileira em Filha moça, sem nenhum herói positivo, sem exemplos saudáveis para a juventude, foi, seguramente, o que guiou a tesoura dos censores.

Como momento de formação do jovem Boal, um dramaturgo al primo canto, a peça, uma experiência deixada para trás, contém elementos que acenam para o futuro da produção do autor, apesar de suas visíveis limitações.

A recusa ao realismo clássico e a busca de um teatro popular é algo que Boal compartilhava com as vanguardas estéticas e, em especial, com o teatro de Brecht. Por que, perguntava Brecht, defender o realismo, essa forma burguesa de expressão, se nem a burguesia está mais interessada nisso? O projeto para se criar um teatro popular levou Boal, desde o início, a permanecer longe do realismo clássico que, no Brasil, era representado pelo TBC.

A busca do popular pode ser constatada, nessa fase inicial, na linguagem utilizada na peça. A norma culta foi deixada de lado e trocada pela fala rudimentar, estropiada, mas necessária.

Com a ressalva de que o texto foi feito para ser representado e não lido, fica a impressão de um autor que olha do alto, que não se coloca no nível de seus personagens. A referência é a norma culta e, em função desta, Boal fez uma marcação exagerada da fala popular. No coloquial, as palavras terminadas em $e$ ou $o$ são pronunciadas em $i$ ou $u$, naturalmente. Assim, tanto na fala popular quanta na do mais empedernido gramático, um admirador incondicional do implacável Napoleão Mendes de Almeida, o hoje vira hoj $i$ e outono vira outon $u$.

Para um linguista mais radical, a marcação exagerada do popular é sinônimo de preconceito linguístico - tema debatido apaixonadamente em 2011 a propósito de um livro didático de língua portuguesa (Por uma vida melhor) adotado pelo MEC, que defendia a linguagem popular. Por conta disso, os jornais passaram a dizer que o MEC pretendia ensinar a falar errado. A discussão, rapidamente, deixou de ser só técnica e passou a ser política. O PT está no poder, o Lula fala errado, logo haveria um empenho governamental populista em glorificar a ignorância do povo brasileiro...

Mas, preconceito por preconceito, os censores da peça foram pioneiros: além de zelarem pelos valores da família brasileira, demostraram empenho e vigilância na defesa da pureza do vernáculo.

Depois de escrever Filha moça, Boal, entre outras muitas coisas, dedicou-se a encenar autores estrangeiros. Tratava-se, segundo ele, de encontrar naqueles autores temas que falassem à realidade brasileira. Boal utilizou a expressão "nacionalização dos clássicos", num momento em que a palavra nacionalização das empresas estrangeiras era agitada pelo movimento nacionalista. Transpondo a reivindicação para o teatro, Boal pôde dizer: "Cansei do realismo e encontrei, 
Boal, assim, manteve-se sempre distante do realismo, mostrando que esse método tem o mérito de constatar as mazelas do mundo, mas é incapaz de contestar. Por isso, critica duramente Plínio Marcos por pretender mostrar a vida como ela é (=constatação). Tal procedimento, dizia ele, tem consequências negativas. A saber: "correm o risco de realizarem a mesma tarefa da caridade em geral e da esmola em particular: a esmola é o preço da culpa”.

Além da crítica à "empatia filantrópica”, Boal aponta o que lhe parece o "obstáculo principal" do realismo: "o diálogo não pode transcender nunca o nível de consciência do personagem" . Afirmação temerária, pois a objetivação da consciência (o diálogo), como ensina a boa dialética materialista, nunca é arbitrária, pois é sempre determinada pelo ser social, pelas condições objetivas da realidade. Pretender conceder autonomia ao diálogo, querer que ele vá além da consciência dos personagens, é voluntarismo. Além disso, um diálogo nem sempre apresenta um sentido unívoco, pois contém contradições internas, reticências que expressam as ambiguidades da consciência do falante, ambiguidades que, por sua vez, são reflexos das tensões existentes na sociedade.

Em defesa de Plínio Marcos, gostaria de lembrar que seus personagens representantes da escória da sociedade - ainda se debatem com o mundo que os marginalizou. Em Navalha na carne, um personagem se pergunta se pessoas como ele e seus iguais ainda são gente, se existe alguma esperança para eles. Nesse momento, o "núcleo humano" se manifesta e se opõe ao processo de reificação. Essa abertura propiciada pelo realismo não existe no naturalismo de Filha moça. Aqui, os personagens não se debatem mais com o mundo e parecem aceitar o destino que lhes foi traçado. $\mathrm{O}$ acachapante objetivismo não deixa nenhum espaço para a inquietação, para a emergência da sofrida subjetividade dos personagens contra uma realidade opressora.

Separando-se desde as primeiras peças do realismo, Boal pode reinventar-se em diversos momentos. Nos tempos em que militou no CPC, pode desenvolver o teatro político de contestação. Voltando ao Arena, no pós-64, as peças como Arena conta Zumbi e Arena contra Tiradentes assinalam um novo período da produção de Boal. A história passada do Brasil era trazida ao presente para animar a luta contra a ditadura. Mas não se trata da reprodução fiel, realista, da história, pois Boal, como observou Cláudia Arruda Campos em seu belo livro, apresentou uma "reprodução irônica ou distorcida de textos históricos". Com tal reprodução, procurava, também, tensionar a instituição teatro. Uma mistura de gêneros e estilos convivia na representação: o circo, a chanchada, o musical. Desse modo, o realismo cedeu lugar à farsa, à fábula, à alegoria, à narrativa naturalista. Com isso, o teatro, em vez de refletir o mundo real, visava à deformação intencional da realidade. Com tal procedimento, ele adquire uma nova função: instrumento de intervenção na realidade, de contestação. Finalmente, no exílio, um Boal maduro criará o Teatro do Oprimido que lhe rendeu uma merecida consagração.

Arriscaria dizer que Boal, como boa parte de sua geração, gravitava em torno da filosofia existencialista, o pensamento hegemônico no período de
5. BOAL, A. Que pensa você do teatro brasileiro? Arte em Revista, n. 2, Ceac/Kairós, 1979, pp. 40-44.

6. CAMPOS, C. A. Zumbi, Tiradentes. São Paulo: Edusp/Perspectiva, 1988, p. 72. Idem: Certo Augusto Boal. Literatura e sociedade, n. 15, 2011. 
formação intelectual de nosso autor. Essa filosofia - que na obra de Sartre aproximava-se cada vez mais do marxismo - opunha-se às concepções essencialistas e estáticas em nome da existência e da liberdade do homem, um ser em incessante devir. Assim, contra a frase "o estilo é o homem" de Buffon, os existencialistas diriam que o homem é o estilo, é ele que faz escolhas, que se faz a si mesmo. Portanto: primeiro a existência, depois a essência.

Com esse referencial, pode-se pensar a trajetória de Boal. Ela nada tem de errática, mas expressa a busca incessante de um espírito inquieto que se questionava o tempo todo para continuar fiel a seus princípios, às suas escolhas - para usarmos uma palavra cara aos existencialistas.

Por outro lado, dando sequência ao projeto das vanguardas estéticas, Boal foi o tempo todo um experimentador, alguém que tensionou a instituição teatro, levando-a a seus limites. O projeto de pôr abaixo a quarta parede trouxe uma fecunda crise para a arte teatral. Este me parece ser o sentido que confere unidade à obra desse grande teatrólogo.

\section{A CENSURA ONTEM E HOJE}

Voltemos à censura. Hoje, após tantas mudanças comportamentais, Filha moça não seria proibida. Na década de 1950, contudo, aquela imagem negativa e rebaixada dos personagens foi vista como uma ameaça para o ideal da família como célula mater da sociedade. Os anos 1960 conheceram a liberação dos costumes, mas a ditadura militar continuava a associar liberação com subversão. Lembro um general que atribuiu a Lênin a pitoresca frase: "corrompa-se a juventude de um país e a revolução será vitoriosa”. Essa associação entre liberação dos costumes e subversão também teve adeptos, à esquerda, entre os leitores de W. Reich que viam no sexo um potencial revolucionário. Santa ingenuidade. O sexo, hoje, tornou-se uma mercadoria, como comprova a rentável indústria da pornografia.

Mas é também ingenuidade acreditar que a censura deixou de existir. A ameaçadora tesoura foi substituída na democracia por uma forma mais sutil de censura, que atende pelo nome de edital - por ironia, uma conquista da classe teatral.

Uma característica importante da vida teatral, hoje, é a existência de um forte movimento: em especial, o teatro amador, contemporâneo dos novos movimentos sociais que se espalharam pelo país.

A movimentação dos coletivos teatrais nos anos 1990 teve sua expressão maior no manifesto Arte contra a barbárie. Não é preciso dizer que o espírito de Boal pairava sobre aqueles grupos de teatro que surgiram na cidade de São Paulo. Todos, de uma forma ou de outra, são continuadores do Teatro do Oprimido. O traço de união era a busca de um teatro popular de formato coletivo, participante, inserido nas preocupações da população local. Isto é, teatro 
não é só um evento, não é trabalho temporário, mas um processo continuado de aprendizagem. Aprendizagem dos atores e, também, formação do público.

$\mathrm{O}$ que os coletivos reivindicavam era um novo sistema de financiamento alternativo à lei Rouanet, pois este transferia o poder de deliberação das políticas culturais do Estado para as empresas privadas. Estas, como se sabe, estavam mais preocupadas com o retorno comercial dos investimentos e nas vantagens publicitárias advindas da união entre a imagem das empresas e os espetáculos artísticos.

Entregue à lógica mercantil, o privilégio passou a ser concedido aos grandes eventos e não ao que é essencial na atividade teatral: a pesquisa, a formação continuada e os vínculos com o público.

Em 2002, os coletivos teatrais conseguiram uma surpreendente vitória: a aprovação da Lei do Fomento ao Teatro da cidade de São Paulo. O importante a observar é que a lei aprovada, indo na contramão do neoliberalismo, vai privilegiar não mais o produto, a montagem das peças, mas o processo de trabalho continuado, o que retira do teatro o viés mercadológico.

Uma nova realidade abriu-se para o pessoal do teatro. Contudo, as vitórias são sempre provisórias e sujeita a reveses. Com verbas escassas, a concorrência se acirrou entre as companhias teatrais e, também, a desconfiança com os critérios adotados e a suspeita em relação aos projetos aprovados. A unidade entre os coletivos foi, então, duramente abalada ${ }^{7}$.

A realização das peças depende agora da aprovação nos editais. Quais os critérios para obter-se a aprovação? Uma nova preocupação passou a ocupar boa parte do tempo dos coletivos: entender o emaranhado jurídico e o caminho das pedras para obter a aprovação.

Colocados na situação de concorrentes, os coletivos procuravam se enquadrar no espírito dos editais. Mas estes são fatores externos ao fazer teatral que, agora, passam a contaminar o trabalho dos artistas. A arte, assim, não obedece aos seus critérios internos, e o "espírito" dos editais, de fora para dentro, passou a contaminar o trabalho artístico.

Para fechar o círculo, um dos critérios dos editais é o "retorno social" do financiamento, os benefícios que a arte pode trazer para a população. O que vem a ser isso?

Para entender melhor o assunto é preciso lembrar que a partir de 2003, durante o primeiro mandato de Lula, houve uma guinada na política cultural: a cultura deixou de ser identificada com as altas produções artísticas e passou a ser vista em termos antropológicos como "um modo de vida", como expressão da vida social. Assim, Gilberto Gil falou na necessidade de se mapear os "pontos de cultura" e na tarefa governamental de realizar um "do in antropológico" para ativar a cultura já existente. Não se trata mais de levar a alta cultura para o povo, mas criar mecanismos para que o próprio povo possa se expressar.

Essa nova concepção, por sua vez, insere-se num movimento internacional. A definição antropológica de cultura também foi encampada anteriormente
7. É ilustrativa das tensões a polêmica surgida em 2011 durante a ocupação da Funarte, que opôs os "trabalhadores da cultura" aos "oficineiros" de Zé Celso. Duas concepções diferentes entraram em conflito: "os que defendem que a apreciação dos resultados de uma política pública cultural deve ser abalizada por critérios inerentes às especificidades do campo artístico e, de outro, os que advogam que os resultados devem ser observados à luz dos processos que o programa permite desenvolver, pois entendem que a preocupação centrada no bem acabado subordina-se mais facilmente aos interesses mercadológicos", MACIEL, Danielle E. F.; OLIVEIRA, Taiguara B. de. Práticas contemporâneas do trabalho com cultura: a Lei do Fomento e o Programa das Fábricas de Cultura. Relato de Pesquisa. ECA, 2016, p. 4. 
pela Unesco, pela ONU, pelo Banco Mundial, pelo Banco Interamericano de Desenvolvimento e pelo FMI.

O súbito interesse dos bancos pela cultura e, em especial, pela cultura popular não tem nada de inocente.

Em primeiro lugar, como se pode ler num documento do MEC, "cultura é um bom negócio". A chamada "economia criativa" vem crescendo em todo o mundo. O peso da indústria cultural no PIB vem crescendo em todos os países.

Além disso, a cultura tem servido para valorizar áreas degradadas das grandes cidades. Um exemplo paulistano: a revitalização da Praça Roosevelt. Uma área degradada tornou-se, graças a ação dos grupos teatrais, um local vivo que passou a atrair a atenção da juventude (depois, como se sabe, a revitalização criada pelo teatro trouxe a valorização imobiliária, o que dificultou a vida dos grupos teatrais).

Finalmente, a cultura passou a ser valorizada como um instrumento de apaziguamento dos conflitos sociais nas comunidades carentes. O estímulo à participação cultural e à criatividade é visto como elemento central para a inclusão social: a arte serviria para manter os jovens longe das drogas e da marginalidade.

Entende-se, assim, o sentido da expressão "retorno social" e o novo papel desempenhado pela cultura: um instrumento para dinamizar a economia, ou, como querem alguns, uma "isca" para o capital. Além disso, a cultura é posta a serviço da inclusão social. A luta de classes cede lugar à inclusão social; a marginalidade é combatida pelos apelos à "participação"; a luta política por direitos sociais é substituída pelo assistencialismo; e a cultura ocupa o lugar que deveria pertencer a educação.

O cenário contemporâneo, onde arte e economia se encontram, é aquele da "cidade criativa", a cidade em que a indústria foi substituída pela prestação de serviços e o trabalho tornou-se uma atividade "criativa" e "empreendedora".

Nessa nova quadra da história, o artista militante foi substituído pela figura jurídica do proponente ${ }^{8}$. Aqueles que não se enquadram, sofrem a ação silenciosa e invisível da implacável censura encoberta pela forma-edital.

8. Cf. OLIVEIRA, T. B. de, O novo protagonismo cultural. Tensões entre coletivos urbanos e políticas públicas (ECA, 2016).

\section{REFERÊNCIAS BIBLIOGRÁFICAS}

BOAL, Augusto. Hamlet e o filho do padeiro. Memórias imaginadas. São Paulo: Cosac Naify, 2014.

. Que pensa você do teatro brasileiro?, Arte em Revista, n. 2, Ceac/ Kairós, 1979.

CAMPOS, Cláudia Arruda. Zumbi, Tiradentes. São Paulo: Edusp/Perspectiva, 1988

Certo Augusto Boal. Literatura e sociedade, n. 15, 2011. 
GERTEL, Vera. Um gosto amargo de bala. Rio de Janeiro: Civilização Brasileira, 2013.

GRAMSCI, Antonio. Cadernos do cárcere. Vol. 6. Rio de Janeiro: Civilização Brasileira, 2002.

MACIEL, Danielle E. F.; OLIVEIRA, Taiguara B. de. Práticas contemporâneas do trabalho com cultura: a Lei do Fomento e o Programa das Fábricas de Cultura. Relato de Pesquisa, ECA, 2016.

OLIVEIRA, Taiguara Belo de. O novo protagonismo cultural. Tensões entre coletivos urbanos e políticas públicas (ECA, 2016). 